\title{
A política de qualificação da saúde suplementar no Brasil: uma revisão crítica do índice de desempenho da saúde suplementar
}

| ${ }^{1}$ Danielle Furtado de Oliveira, ${ }^{2}$ George Edward Machado Kornis |

Resumo: Trata-se de uma revisão teórica de caráter exploratório que objetivou compreender o papel do Índice de Desempenho da Saúde Suplementar (IDSS) do Programa de Qualificação de Operadoras de Planos de Saúde, elaborado pela Agência Nacional da Saúde Suplementar (PQSSANS). A proposta de trabalho consistiu em ampliar os conhecimentos sobre a trajetória desse índice, bem como o impacto do seu uso para regulação e concentração do setor através da análise dos documentos oficiais e dos trabalhos acadêmicos produzidos sobre o tema. Percebeu-se nesta revisão que a literatura acadêmica é extremamente escassa sobre essa temática, o que por si só justifica a necessidade de realizar mais estudos sobre a PQSS. A pesquisa concluiu que o instrumento utilizado pela ANS é eficaz, democrático e participativo no que diz respeito ao alcance dos objetivos do Programa de Qualificação das Operadoras de Planos de Saúde, pois promoveu maior transparência ao subsistema privado. No entanto, constatou-se também que o IDSS teve um papel saneante e concentrador do mercado em favor dos oligopólios privados, indo de encontro aos preceitos normativos da ANS em defesa do consumidor, da concorrência regulada e do interesse público.

> Palavras-chave: saúde suplementar; avaliação dos sistemas de saúde; sistema de informação; programa de qualificação.

\author{
1 Núcleo de Inovação \\ Tecnológica, Instituto \\ Nacional de Traumatologia \\ e Ortopedia, Ministério da \\ Saúde. Rio de Janeiro-RJ, Brasil \\ (daniellefurtadooliveira@ \\ gmail.com) \\ ${ }^{2}$ Instituto de Medicina Social, \\ Universidade do Estado do Rio \\ de Janeiro. Rio de Janeiro-RJ, \\ Brasil (gkornis@gmail.com).
}

Recebido em: 06/09/2015 Aprovado em: 21/01/2017 


\section{Considerações iniciais}

Este artigo é fruto de uma dissertação de mestrado que trata dos caminhos da avaliação de desempenho do setor de saúde, tanto do segmento público quanto do privado, no Brasil. No entanto, neste estudo, a análise se concentra na avaliação de desempenho da saúde suplementar, sendo o exame do Índice de Desempenho da Saúde Suplementar (IDSS) o núcleo desta revisão.

O objetivo deste estudo foi investigar na literatura o papel que o IDSS, parte integrante do Programa de Qualificação de Operadoras de Planos de Saúde, elaborado pela Agência Nacional da Saúde Suplementar (ANS), tem desempenhado no setor privado da saúde brasileira. A proposta de trabalho consistiu em ampliar os conhecimentos sobre a trajetória desse índice, bem como o impacto do seu uso para a regulação do setor. O que se percebeu é que a literatura acadêmica é extremamente escassa sobre essa temática, o que por si só justifica a necessidade de realizar mais estudos sobre a Política de Qualificação da Saúde Suplementar.

No país, pode-se dizer que temos um "sistema de saúde duplicado", onde os arranjos entre o público e o privado do sistema misto de saúde coexistem no provimento, financiamento, demanda e utilização dos serviços de saúde. Ressalta-se ainda o caráter suplementar do sistema, quando o segmento opera em países com Sistema Nacional de Saúde, oferecendo elementos adicionais, tais como hotelaria, livre escolha, maior rapidez ou serviços e tecnologias ainda não cobertos pelo sistema público. Quando há a comercialização de serviços já oferecidos no sistema público, ocorre uma cobertura duplicada, como é o caso de Reino Unido, Portugal, Espanha, Itália, Grécia e Brasil.

No sistema de saúde brasileiro, "com o seguro suplementar e de cobertura duplicada, temos alguns paradoxos que não diferem muito daqueles verificados em países com o mesmo tipo de mix" (SANTOS, 2009, p. 23), mas existem particularidades relativas a nossa formação social. Por exemplo, o percentual da população coberta pelo segmento suplementar é aqui muito mais expressivo, sendo praticamente o dobro dos países referidos, o que pode estar relacionado com problemas na qualidade e no financiamento do sistema público (FAVERET FILHO; OLIVEIRA, 1990). 
No caso do Brasil, o crescimento do setor privado - traduzido na prestação

de serviços por unidades privadas, ou na existência de formas privadas de financiamento, gestão e acesso a serviços de saúde - é anterior ao movimento de valorização do mercado, fruto das reformas econômicas dos anos 1990 no país. Portanto, não pode ser visto como uma simples resposta às pressões e mudanças geradas na conjuntura nacional e internacional.

A saúde suplementar no Brasil, então, pode ser definida como todo atendimento privado de saúde, realizado ou não por meio de um convênio com um plano de saúde. Estão presentes dentro do cenário da Saúde Suplementar no Brasil o governo - representado pelo Ministério da Saúde -, a Agência Nacional de Saúde Suplementar (ANS) e a Agência Nacional de Vigilância Sanitária (Anvisa) -, além das operadoras de planos privados, as seguradoras e os prestadores de serviço de assistência à saúde.

O sistema suplementar de saúde é composto mais amiúde pelos serviços prestados por seguradoras especializadas em seguros-saúde, empresas de medicina de grupo e odontologia de grupo, cooperativas (especializadas em planos médico-hospitalares e/ou odontológicos), entidades filantrópicas, companhias de autogestão e administradoras. Estas últimas são, segundo definição da ANS, "empresas que administram planos de assistência à saúde financiados por outra operadora”.

As operadoras compram dos prestadores de serviços da área de saúde (médicos, laboratórios, clínicas, hospitais etc.) serviços como consultas, exames, internações, cirurgias, tratamentos, entre outros. Para tanto, dispóem de carteira de clientes (conveniados ou segurados) que, a partir de contratos, remuneram as operadoras de planos e seguros-saúde por meio de mensalidades. Existem aqueles consumidores que fazem uso dos serviços privados da saúde através do desembolso direto dos recursos. Estes não sofrem as inferências promovidas pelo Programa de Qualificação da ANS, pelo menos não diretamente.

Pode-se dizer que o setor suplementar da saúde existe há mais de 70 anos. Inicialmente, para Carvalho e Cecílio (2007), a assistência médica foi incorporada como benefício a grupos de trabalhadores brasileiros a partir da década de 1930, com a criação das CAPs e dos IAPs. Contudo, sabe-se também que o mercado de planos privados de assistência à saúde no Brasil se desenvolveu e expandiu, 
segundo Costa (2008), num contexto institucional de baixa regulação, situação que perdurou até fins da década de 1990.

No período de existência das diversas modalidades de atenção privada à saúde, não houve barreiras de entrada e saída para novas empresas ou qualquer outro mecanismo de controle que pudesse assegurar a qualidade do serviço prestado. As queixas contra planos e seguros saúde estavam entre as cinco primeiras causas de reclamaçôes na Fundação de Defesa do Consumidor (Procon) de São Paulo e do Rio de Janeiro, entre 1992 e 1996.

Para Carvalho e Cecílio (2007), a regulamentação foi inserida na agenda política nacional justamente em função dessas queixas dos usuários/consumidores e dos conflitos no relacionamento médico/usuário/operadoras de plano de saúde. Nesse contexto, segundo Oliveira (2013), com quase quarenta anos de funcionamento sem regulação, o mercado de planos e seguros privados de atenção à saúde, no Brasil, denominado Saúde Suplementar, teve que se adequar e cumprir a regulamentação trazida pela Lei no 9.656, de 03 de junho de 1998.

Segundo Costa (2008), o marco regulatório do setor foi constituído pela Lei ${ }^{\circ}$ 9.656/98, mas também pela criação da ANS em 2000 (BRASIL, 1998; 2000a). Tais medidas modificaram significativamente o cenário do setor, pela definição de novas regras de proteção aos consumidores e de entrada, permanência e saída das empresas no mercado. Sendo assim, à ANS coube promover a defesa do interesse público na assistência suplementar à saúde e regular as operadoras setoriais, inclusive em suas relaçōes com prestadores de serviço e consumidores, contribuindo para o desenvolvimento das ações de saúde.

Segundo Caetano, Prado e Pietrobon (2008), o modelo brasileiro de regulação do setor de saúde suplementar é diferenciado em relação à experiência internacional. $\mathrm{Na}$ maioria dos países, a regulação é feita a partir da atividade econômica em si, atuando sobre as empresas do setor e garantindo suas condiçóes de solvência e a competitividade do mercado.

No Brasil, optou-se por regular fortemente o produto oferecido, ou seja, a assistência à saúde, com medidas inovadoras, como a proibição da seleção de risco e do rompimento unilateral dos contratos. Para Bahia e Viana (2002), a regulação brasileira tem como objetivos principais corrigir as distorções quanto às seleções de risco e preservar a competividade do mercado. Conforme Majone (1996), o interesse público pode ser preservado e desenvolvido frente às atividades 
de mercado, por meio de controles legais e incentivos organizacionais manejados externamente por uma agência reguladora.

De acordo com a própria ANS (2010), a regulação trouxe mudanças importantes que fizeram e fazem com que o ambiente da saúde suplementar esteja melhor hoje do que no período pré-regulamentação. Com um número de beneficiários maior que 70 milhões, a ANS é uma realidade e uma necessidade do setor no país dos dias atuais, embora ajustes necessitem ser feitos no seu modus operandi (ANS, 2016).

Esses avanços, segundo Oliveira (2013), permitiram que a ANS encarasse de forma diferente os desafios que lhe são impostos, um dos quais é a regulação indutora com foco na qualidade e o empoderamento do usuário/beneficiário/ consumidor como sujeito da regulação. Nesse sentido, a ANS vem adotando, desde 2005, uma Política de Qualificação da Saúde Suplementar, que abarca uma nova perspectiva no processo de regulação. Em última instância, tal processo busca: incentivar as operadoras a atuarem como gestoras de saúde; incentivar os prestadores a atuarem como produtores de saúde; incentivar os beneficiários a se tornarem usuários de serviços de saúde com consciência sanitária; e aprimorar a capacidade de regulação da ANS, voltada para tais objetivos. Um dos braços dessa política é o Programa de Qualificação da Saúde Suplementar, do qual o IDSS, foco deste artigo, é produto.

Todavia, se faz importante mencionar que, apesar dos avanços supracitados, existem evidências de que o modelo regulatório empregado pela ANS vem, por outro lado, corroborando para o saneamento do setor da saúde suplementar e o acirramento da competição, principalmente em favor dos oligopólios privados (OCKÉ-REIS, 2004), indo de encontro aos preceitos normativos da ANS de defesa do consumidor, da concorrência regulada e do interesse público.

\section{Revisão de literatura}

Partindo desse norte, a Resolução no 139, de 24 de novembro de 2006 (ANS, 2006), instituiu o Programa de Qualificação da Saúde Suplementar no âmbito do sistema de saúde suplementar, como parte integrante da política de qualificação da saúde suplementar da ANS. Esta, ao explicitar sua política de regulação enquanto política de qualificação para o setor de saúde suplementar, explicitou 
também as finalidades para o setor, condensadas na diretriz-mestra de fazer do setor um local de produção de saúde. Uma das estratégias dessa política postas pela agência é a avaliação da qualidade do setor da saúde suplementar.

Para essa avaliação, a ANS apresentou como prioridade de intervenção o desenvolvimento do Programa de Qualificação da Saúde Suplementar, que se desdobra em dois componentes: I) Avaliação de Desempenho das Operadoras ou Qualificação das Operadoras; e II) Avaliação de Desempenho da ANS ou Qualificação Institucional.

No artigo $6^{\circ}$ da citada resolução, as avaliações de desempenho são expressas pelos seguintes índices: I) Índice de Desempenho da Saúde Suplementar da Operadora - IDSS; e II) Índice de Desempenho Institucional - ID.

O índice de desempenho das operadoras foi aplicado pela primeira vez tomando como base os dados de 2004 e se manteve sua verificação anualmente, com algumas alterações na composição da cartela de indicadores. Ele é resultante da avaliaçãoo da qualidade em quatro dimensões: I) Atenção à Saúde; II) EconômicoFinanceira; III) Estrutura e Operação; e IV) Satisfação dos Beneficiários.

Em relação ao componente Qualificação das Operadoras, foco desta pesquisa, a ANS pretendia induzir um processo de aprimoramento contínuo nas quatro dimensões acima, para que o setor da saúde suplementar operasse de forma equilibrada, ágil, com informaçôes consistentes, oferecendo serviços adequados a seus beneficiários. Dessa maneira, essas dimensões são avaliadas por meio de indicadores gerais e específicos, que buscam expressar os condicionamentos e os resultados dos serviços prestados aos beneficiários pelos planos de saúde.

Para Caetano, Prado e Pietrobon (2008), a ANS possui excelentes possibilidades com a criação, verificação e divulgação de indicadores da qualidade da promoção e dos cuidados integrais da saúde, e a busca pela qualificação das operadoras de seguros de saúde impulsiona a regulação.

Assim, com o intuito de explanar o processo de construção metodológica do IDSS, optou-se por realizar uma descrição a partir dos seguintes aspectos: fundamentação teórica; democratização do debate metodológico; comparabilidade dos indicadores ano a ano; métodos estatísticos, parâmetros e pontuação aplicados; histórico do componente qualificação das operadoras e resultados encontrados. Todos são descritos a seguir: 
A preocupação de verificar os índices de qualidade das operadoras de planos de saúde que compõem o universo da saúde suplementar surge da necessidade de propor novos modelos assistenciais.

Pesquisa feita por Malta et al. (2005) sobre os modelos assistenciais desenvolvidos pelas operadoras de planos de saúde identificou que elas, cada uma com suas especificidades, representam certos modelos de organização de serviços de saúde que podem ser regulados pelo Estado, de forma a darem maiores garantias assistenciais a seus beneficiários. Também foi identificada como uma perspectiva real, nesta pesquisa, a possibilidade de as operadoras se constituírem enquanto promotoras e gestoras do cuidado em saúde, e que isso pode ser regulado.

Para buscar a qualificação da atenção desse setor, foi necessário que a ANS desencadeasse um processo de monitoramento e avaliação na perspectiva da atenção à saúde, de forma a instituir o novo modelo de regulação com novos processos e práticas de micro e macrorregulação que induzissem à reversão da atual lógica de organização e funcionamento do setor.

$\mathrm{Na}$ revisão bibliográfica do programa de qualificação da ANS, foram consultadas referências nacionais, como o "Projeto de desenvolvimento de metodologia de avaliação de desempenho do sistema de saúde brasileiro PROADESS", coordenado pela Fiocruz e realizado por diversas instituições acadêmicas e de serviço do país, internacionais, como os estudos do Australian Institute of Health and Welfare ${ }^{1}$ e do Hedis, além de publicações disponíveis na Scielo $^{2}$ e outras fontes de literatura.

A seleção dos indicadores buscou privilegiar aqueles que pudessem ter sua viabilidade contemplada pela disponibilidade de dados gerados de forma regular e manejados em sistemas de informaçóes gerenciados pela ANS. O Sistema de Registro de Produtos (RPS), o Sistema de Informações de Beneficiários (SIB), o Sistema de Informações de Produtos (SIP), o Cadastro de Operadoras (Cadop), o Cadastro Nacional dos Estabelecimentos de Saúde (CNES/Datasus/MS) e o Documento de Informações Periódicas das Operadoras de Planos de Assistência à Saúde (Diops) foram as principais fontes utilizadas. 


\section{Democratização do debate metodológico}

Durante o processo de implementação do Programa de Qualificação de Operadoras de Planos de Saúde, houve a oportunidade de a sociedade participar, enviando contribuições através de consulta pública, com o preenchimento do formulário específico publicado no site da ANS na internet. As propostas foram redigidas com base nas discussóes da Câmara Técnica criada especificamente para tratar do assunto. A última consulta sobre o Programa de Qualificação, Consulta Pública no 46, que apresentou proposta para revisão dos indicadores componentes do IDSS, ocorreu de 28 de setembro a 4 de novembro de 2011.

É importante ressaltar que, desde seu lançamento, segundo a ANS (2010), o Programa de Qualificação da Saúde Suplementar foi respaldado por discussōes e aprovaçōes unânimes dos diretores da ANS, tanto em seus fundamentos, quanto em suas fases de implantação e de divulgação de resultados, sendo todas as decisões registradas nas atas das reuniōes da diretoria colegiada, rotineiramente divulgadas no site da ANS na internet.

\section{A comparabilidade dos indicadores ano a ano}

Os indicadores de avaliação da qualidade das dimensões da Atenção à Saúde, Econômico-Financeira, Estrutura e Operação e de Satisfação dos Beneficiários, da primeira fase, foram definidos em função dos dados disponíveis. Em cada fase ou etapa foram incorporados novos indicadores, cujos dados estavam disponíveis, considerando o tempo necessário para que as operadoras ajustassem seus sistemas de informações.

No primeiro processamento, competência 2003, a identificação dos indicadores de atenção à saúde, que constituiu objeto de análise da qualificação da operadora, ocorreu por intermédio dos dados informados no Sistema de Informações de Produtos. Nos processamentos seguintes, utilizaram-se na análise o Sistema de Informações de Beneficiários, o Sistema de Registro de Planos de Saúde e de Cadastro de Planos anteriores à Lei no 9.656/98 para identificar a segmentação assistencial de atuação da operadora e, consequentemente, os indicadores por ela devidos.

A partir de 2011, foi inaugurada a quarta fase do Programa de Qualificação de operadoras, objetivando a continuidade do aprimoramento da qualidade dos 
serviços prestados aos beneficiários, a transparência das informações, bem como o atendimento aos objetivos assinalados pela Agenda Regulatória da ANS.

\section{Métodos estatísticos, parâmetros e pontuação aplicados}

Tanto o componente de qualidade das operadoras quanto o da avaliação institucional são aferidos por índices de desempenho, calculados a partir da análise de indicadores definidos pela ANS. O processo de aferição é gradual e progressivo, permitindo flexibilidades e mudanças quando necessárias.

O Índice de Desempenho varia entre zero e um. Valores próximos a um indicam que a atuação da operadora está em conformidade ao estabelecido pela ANS, enquanto valores próximos a zero indicam atuação distante do estabelecido pela ANS, na fase e período analisados. O índice é elaborado por indicador, dimensão, conjunto de operadoras por segmentação assistencial (médicohospitalar e exclusivamente odontológico), modalidade e porte, bem como um índice geral do Setor da Saúde Suplementar.

$\mathrm{Na}$ elaboração do IDSS de um conjunto de operadoras por segmentação assistencial (médico-hospitalar e exclusivamente odontológico), modalidade ou porte por número de beneficiários, há ponderação pelo número médio de beneficiários no período analisado. As operadoras avaliadas são as que estão com registro ativo junto à ANS no período analisado. As operadoras que iniciarem atividades ou ampliarem a cobertura assistencial comercializada, no decorrer do período analisado, só serão avaliadas no período seguinte, garantindo o período de 12 meses de atuação no mercado.

A pontuação obtida pela operadora em cada indicador constitui a base de cálculo do Índice de Desempenho de cada dimensão e do IDSS. Os indicadores são calculados por intermédio dos dados enviados pelas operadoras aos Sistemas de Informações da ANS, dados da própria Agência ou de Sistemas Nacionais de Informações em Saúde, como do Sistema de Informaçôes Hospitalares (SIH) e o Cadastro Nacional de Estabelecimentos de Saúde (CNES).

Para cada indicador, foi estabelecida uma graduação de pontuação, conforme o resultado que a operadora obteve para aquele indicador. Assim, o componente da Qualificação das Operadoras avalia o desempenho das operadoras por meio de seu IDSS. Como já dito, esse índice varia de zero a um (0-1), sendo que 40\% 
desse valor é dado pelo Índice de Desempenho da Atenção à Saúde (IDAS); 20\% pelo Índice de Desempenho Econômico-financeiro (IDEF); 20\% pelo Índice de Desempenho de Estrutura e Operação (IDEO) e 20\% pelo Índice de Desempenho da Satisfação dos Beneficiários (IDSB).

Cada um desses índices é medido por um grupo de indicadores. O resultado do Índice de Desempenho de cada dimensão é dado pelo quociente entre a soma dos pontos obtidos pela operadora em cada indicador e a soma do máximo de pontos possível de todos os indicadores específicos daquele índice que foram aplicados à operadora avaliada.

Cabe ressaltar, ainda, que os pesos dos indicadores que compõem cada índice representativo de cada dimensão que constitui o IDSS variam e que, em ordem decrescente (do maior peso para o menor) de importância, estariam arranjados da seguinte maneira: IDAS (tratamento, promoção e prevenção); IDEO (disponibilidade e acesso); e IDEF (sustentabilidade, risco e liquidez).

\section{Métodos estatísticos aplicados nos indicadores do IDSS}

As taxas em pequenas populaçõos podem sofrer grande variação com a adição ou subtração de um único evento. Várias operadoras possuem poucos beneficiários e suas taxas para determinado evento podem mudar bruscamente de valor se um único evento é adicionado ou subtraído ao total de casos ocorridos.

Existem metodologias estatísticas que buscam eliminar esse efeito de variação das taxas em pequenas populaçooes, fazendo uma estimativa dessas taxas. São os chamados "métodos bayesianos". A metodologia estatística aplicada foi Bayes Empírico, também conhecida como método de contração (shrinkage method, em inglês), um dos mais simples e práticos métodos de estimação bayesiana. É também uma metodologia estatística que visa ajustar as flutuações extremas das taxas e proporções em pequenas populações.

A metodologia consiste em ajustar a taxa de um evento, encontrada em cada operadora, pela taxa média de todas as operadoras para aquele evento em questão, considerando o número de beneficiários de cada operadora e a dispersão dos valores das taxas entre operadoras. Quanto menor for o número de beneficiários de uma operadora expostos a um evento ou procedimento (denominador de alguns indicadores), maior será o ajuste, ficando a taxa da operadora próxima da 
taxa média de todas as operadoras. Quanto maior for o número de beneficiários

expostos (denominador de alguns indicadores), menor será o ajuste pela taxa média de todas as operadoras, ficando a operadora com a taxa ajustada muito próxima daquela sem ajuste encontrada para ela.

A metodologia bayesiana considera um terceiro fator: a dispersão das taxas individuais das operadoras em torno da taxa média de todas as operadoras. Quanto maior for essa dispersão, menor é o ajuste efetuado.

No cálculo do Bayes Empírico, a taxa estimada é dada pela multiplicação da taxa encontrada para a operadora (taxa sem ajuste ou taxa bruta) por um Fator de Ajuste; somado à taxa média do conjunto das operadoras multiplicada por um menos o Fator de Ajuste. Quanto menor o valor do denominador do indicador, mais próximo de zero será o Fator de Ajuste, fazendo com que a taxa bruta calculada para a própria operadora contribua pouco no valor da taxa estimada e ficando esta muito próxima ao valor da taxa média de todas as operadoras. Por outro lado, quanto maior o valor do denominador do indicador, mais próximo de um será o Fator de Ajuste, fazendo com que o valor da taxa estimada seja muito próximo ao valor da taxa bruta da operadora, com pouca influência da taxa média de todas as operadoras.

Um terceiro fator que afeta o grau de ajuste é a dispersão das taxas individuais das operadoras em torno da taxa média de todas as operadoras do setor. Quanto maior for essa dispersão, menor será o fator de ajuste. Esse terceiro fator afeta globalmente o ajuste de todas as operadoras.

Segundo documento emitido pela ANS (2011), a metodologia estatística da Padronização Indireta por Faixa Etária e Sexo visa eliminar a influência causada nos resultados de alguns indicadores pela composição quantitativa diferenciada das faixas etárias e sexo da população beneficiária de cada operadora. Observouse ainda, no referido documento, que a padronização indireta está indicada para quando não se dispóe de dados que permitam calcular de forma precisa e acurada as taxas de cada operadora por faixa etária e sexo.

A metodologia consiste em estimar inicialmente um valor de referência: qual seria o número de eventos na população de cada operadora se elas tivessem a mesma taxa da população de referência em cada faixa etária e sexo. A seguir, calculamse quantos eventos a mais ou a menos em relação ao valor de referência foram 
realmente observados em cada operadora. Os números relativos aos valores de referência das várias operadoras podem ser comparados entre si, pois as diferenças causadas pelas diferenças de composição etária e por sexo foram eliminadas.

Já a Padronização Indireta por Faixa Etária ou por Faixa Etária e Sexo se dá pela multiplicação das taxas per capita encontradas nas faixas de idade e sexo de uma população de referência, pelos correspondentes quantitativos de beneficiários, em cada faixa de idade e sexo, de cada operadora. Somam-se os valores obtidos para as faixas etárias e sexo da operadora, encontrando o número total esperado de eventos na operadora, caso ela estivesse submetida ao mesmo padrão de risco da população de referência. Divide-se o número de eventos informados pela operadora pelo número de eventos esperados para ela, encontrando-se uma razão para padronização, aqui denominada "Razão Informados Esperados" (RIE).

O RIE de cada operadora é multiplicado por uma taxa de referência (ex: taxa média da população de referência), encontrando-se a taxa padronizada da operadora. As taxas padronizadas das operadoras passam a ser comparáveis entre si, sem a influência dos quantitativos diferenciados de faixas etárias e sexo.

\section{Histórico do componente qualificação das operadoras}

A implantação do Programa de Qualificação da Saúde Suplementar foi aprovada por unanimidade pela Diretoria Colegiada da ANS em novembro de 2004, e o programa vem sendo implementado progressivamente.

A Avaliação da Qualidade das Operadoras, focada nas quatro dimensões citadas, foi planejada para ser implementada em três fases, tendo sido previstos para cada fase aperfeiçoamentos ou substituiçōes de indicadores inicialmente estabelecidos, além de acréscimos de novos indicadores, levando sempre em consideração critérios técnicos de eleição de indicadores, consagrados por diversos modelos de avaliação, como validade, confiabilidade, viabilidade e relevância.

O Programa de Qualificação de Operadoras já passou por quatro fases até os dias atuais, descritas na tabela a seguir, elaborada a partir das principais características de cada fase: 


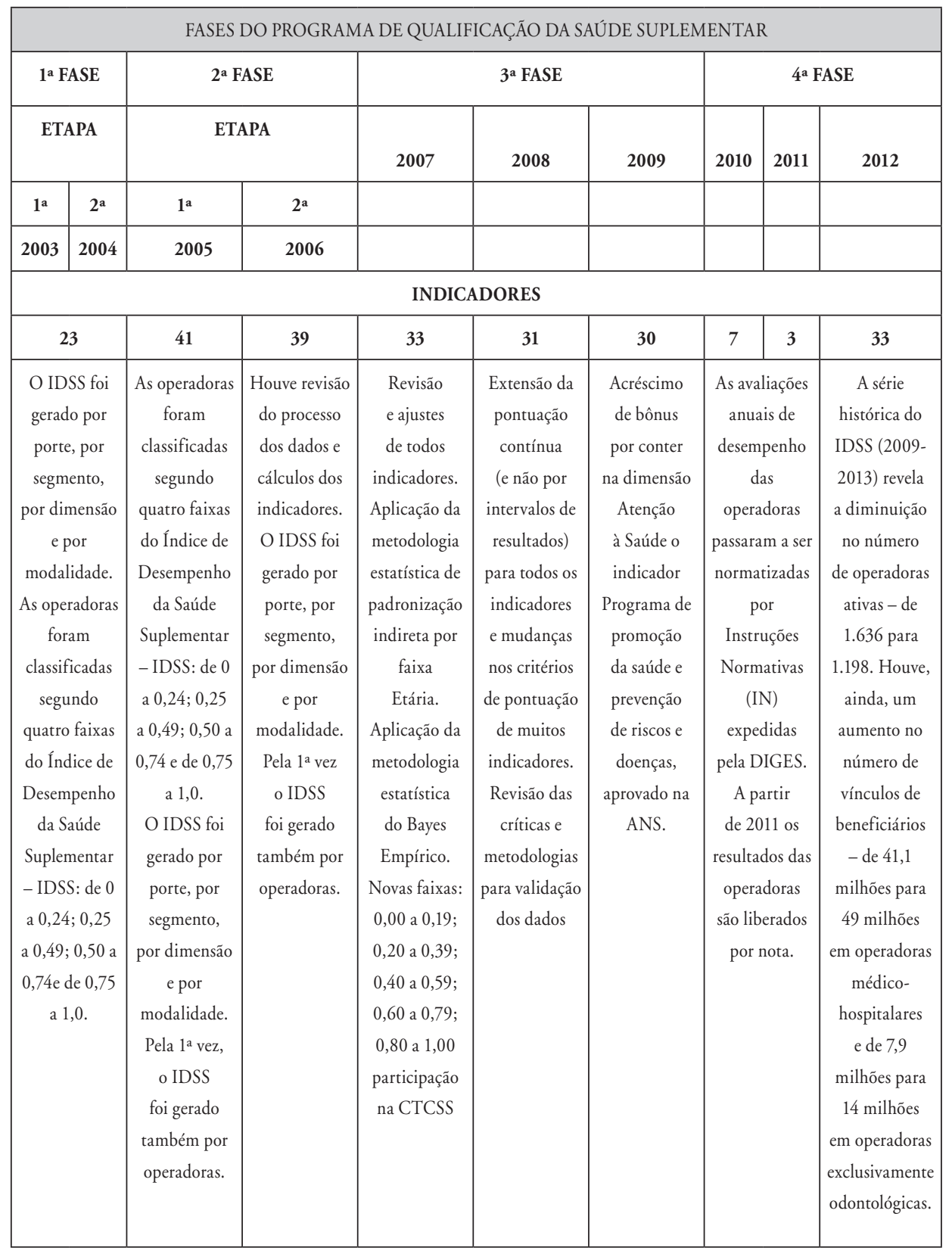




\section{A última atualização do IDSS}

Com o objetivo de promover seu aprimoramento, a ANS está aperfeiçoando o IDSS novamente. As novas dimensões do índice são resultado do alinhamento aos eixos direcionais da ANS, à agenda regulatória e à literatura de qualidade em saúde.

O IDSS 2016 continuará com 4 dimensões, mas apresentadas na seguinte composição:

- Qualidade em atenção à saúde: avaliação do conjunto de ações em saúde que contribuem para o atendimento das necessidades dos beneficiários, com ênfase nas ações de promoção, prevenção e assistência à saúde prestada;

- Garantia de acesso: condições relacionadas à rede assistencial que possibilitam a garantia de acesso, abrangendo a oferta de rede de prestadores;

- Sustentabilidade no mercado: monitoramento da sustentabilidade da operadora, considerando seu equilíbrio econômico-financeiro, passando pela satisfação do beneficiário e compromissos com prestadores;

- Gestão de processos e regulação: entre outros indicadores, essa dimensão afere o cumprimento das obrigações técnicas e cadastrais das operadoras junto à ANS.

As novas dimensões estão mais interligadas e têm o mesmo peso: $25 \%$. Segundo a ANS (2016b), essas modificações promoverão maior estímulo à qualidade do setor, buscando a integração do PQSS a outros programas de qualidade tais como o Programa de Acreditação de Operadoras e Programa de Qualificação de Prestadores - Qualiss.

\section{Métodos}

Trata-se de uma pesquisa exploratória, cuja ideia central foi realizar uma revisão de literatura sobre o IDSS, levando em consideração a contradição que abarca esse modelo regulatório via indução da qualificação e os avanços promovidos para o setor privado da saúde pela utilização do índice. A análise transcorreu a partir tanto dos documentos oficiais pertinentes quanto da literatura acadêmica relevante produzida até julho de 2016 sobre a temática da pesquisa.

Desse modo, para alcançar os objetivos da pesquisa, além da leitura da fonte de documentos oficiais produzidos pela ANS, pelo Ministério da Saúde, pelo Instituto de Estudos da Saúde Suplementar, pela Federação de Seguros e pela 
Associação Brasileira de Medicina de Grupos, foram analisados os sistemas de informação do Datasus (TABnet) e o Espaço Qualidade, link do site da ANS, a fim de evidenciar o processo de implantação e utilização do programa de qualificação da ANS através dos anos.

Somado a isso, com o intuito de analisar o IDSS sob uma perspectiva crítica, também foram consultados na plataforma da Biblioteca Virtual de Saúde (BVS) trabalhos acadêmicos produzidos até julho de 2016 sobre o Programa de Qualificação da ANS. A busca na BVS se deu por meio dos seguintes descritores: IDSS; Índice de desempenho da saúde suplementar; Programa de qualificação da saúde suplementar; PQSS; e Política de qualificação. De um total de trinta e três trabalhos gerados pela busca a partir desses descritores, apenas seis se referiam ao IDSS propriamente dito, duas dissertaçōes, três artigos e um trabalho exposto em uma mostra do Ministério da Saúde. Tal fato dificultou uma análise crítica mais aprofundada acerca dos impactos causados pela utilização do IDSS pela ANS.

\section{Resultados e discussão}

Os resultados desta pesquisa permitem observar que há uma escassez de trabalhos acadêmicos realizados sobre a Saúde Suplementar, neste caso, mais precisamente, sobre a avaliação de desempenho do setor. Subtraindo os documentos oficiais, apenas seis documentos tratavam da qualificação da saúde suplementar, o que reforça a necessidade de uma maior apropriação do modus operandi do subsistema privado da saúde pelos pesquisadores do setor. Essa necessidade parte da premissa de que o Sistema de Saúde Brasileiro é dual, portanto, composto do segmento público (SUS) e do segmento privado (mercado de planos privados de saúde), conforme tem argumentado Bahia (2005).

É importante destacar que o mercado de planos de saúde no Brasil não é composto por um empresariado homogêneo. Muito pelo contrário, trata-se de um mercado composto por uma diversidade de empresas, denominadas de operadoras de planos de saúde, com diferentes portes, diferentes arranjos jurídicoinstitucionais, com e sem fins lucrativos, que têm em comum, basicamente, a atividade de comercializar planos de saúde (SCHEFFER; BAHIA, 2013).

A despeito dos resultados gerados pelo IDSS, no período compreendido entre os anos-base 2004 a $2014^{3}$, observou-se, conforme dados da ANS, uma 
diminuição no número de operadoras ativas, avaliadas pela Qualificação das Operadoras, e um aumento no número de beneficiários.

No segmento médico-hospitalar, o percentual de operadoras situadas nas duas melhores faixas do IDSS manteve o equilíbrio em relação aos últimos dois anos, dando continuidade à evolução positiva da série histórica. Em relação às duas faixas de pior avaliação, também houve uma estabilização nos últimos três anos. O IDSS de 2013, por exemplo, revelou que 94,6\% dos beneficiários de planos de saúde do país estão em operadoras que obtiveram nota igual ou superior à metade da pontuação máxima - ou seja, estão em operadoras com avaliação regular, boa ou muito boa. Abaixo se encontra representada no gráfico 1 essa distribuição das operadoras pelas faixas de resultados em série histórica:

Gráfico 1. Distribuição percentual das operadoras médico-hospitalares ${ }^{4}$ por faixas de IDSS

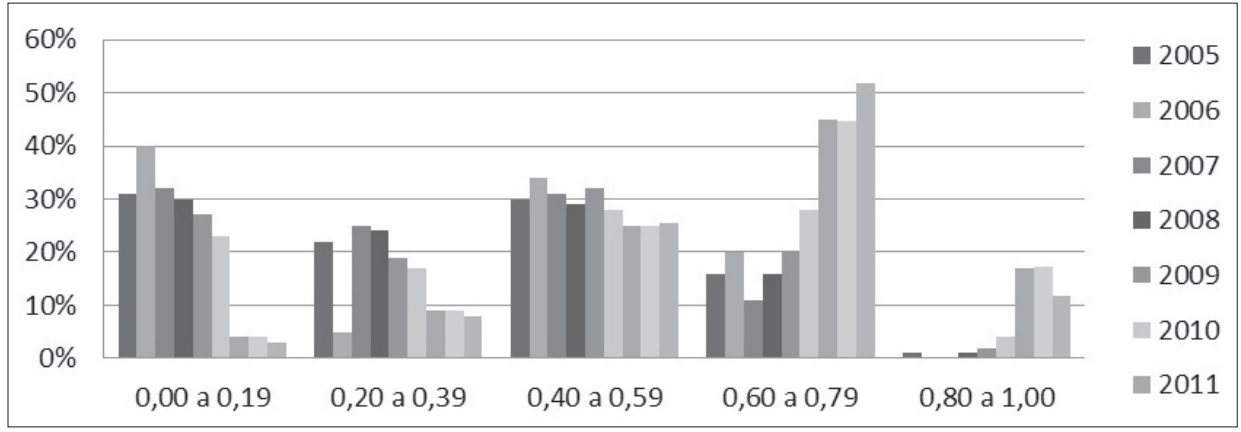

Já em relação ao percentual de beneficiários de planos médico-hospitalares, houve um aumento do percentual de beneficiários situados nas duas melhores faixas de IDSS, passando de $76 \%$, no ano-base 2011 , para $83 \%$ no ano base 2013. Nas duas piores faixas, verificou-se redução de $3 \%$ para $2 \%$ no período em questão (ANS, 2014), como demonstrado no gráfico a seguir: 
Gráfico 2. Distribuição percentual dos beneficiários de planos médico-hospitalares por faixas de IDSS

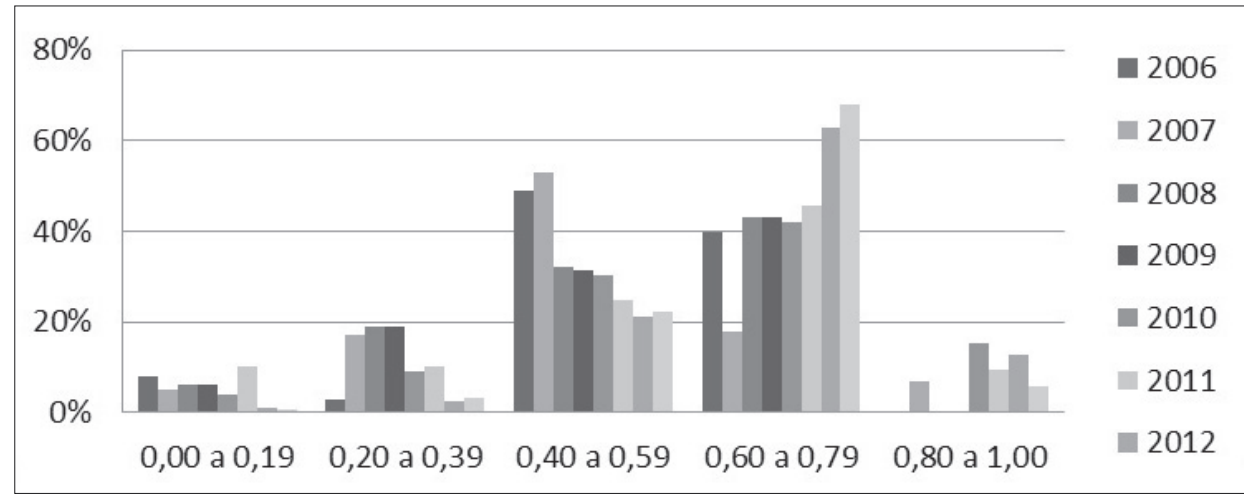

$\mathrm{Na}$ avaliação das operadoras exclusivamente odontológicas, observou-se que, nas duas melhores faixas de IDSS, o percentual de operadoras evoluiu de 52\%, em 2011, para 61\% no ano-base 2013, enquanto que, nas duas faixas menores, houve manutenção no patamar de $19 \%$ nos últimos três anos, como se pode constatar no gráfico 3:

Gráfico 3. IDSS exclusivamente odontológico por operadora

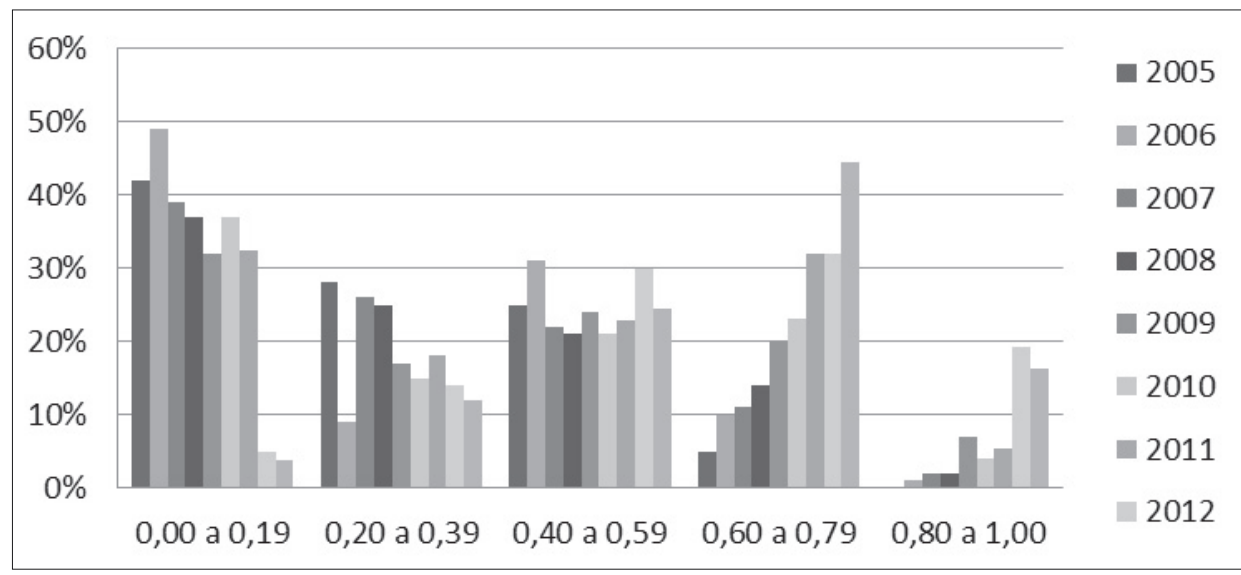


Observou-se que, nas duas melhores faixas de IDSS, o percentual de beneficiários aumentou de $76 \%$ para $92 \%$. Nas duas piores faixas de avaliação, identificou-se uma redução de 4\%, em 2011, para 3\% no ano-base 2013 (ANS, 2014), conforme o gráfico 4 .

\section{Gráfico 4. IDSS exclusivamente odontológico por beneficiário}

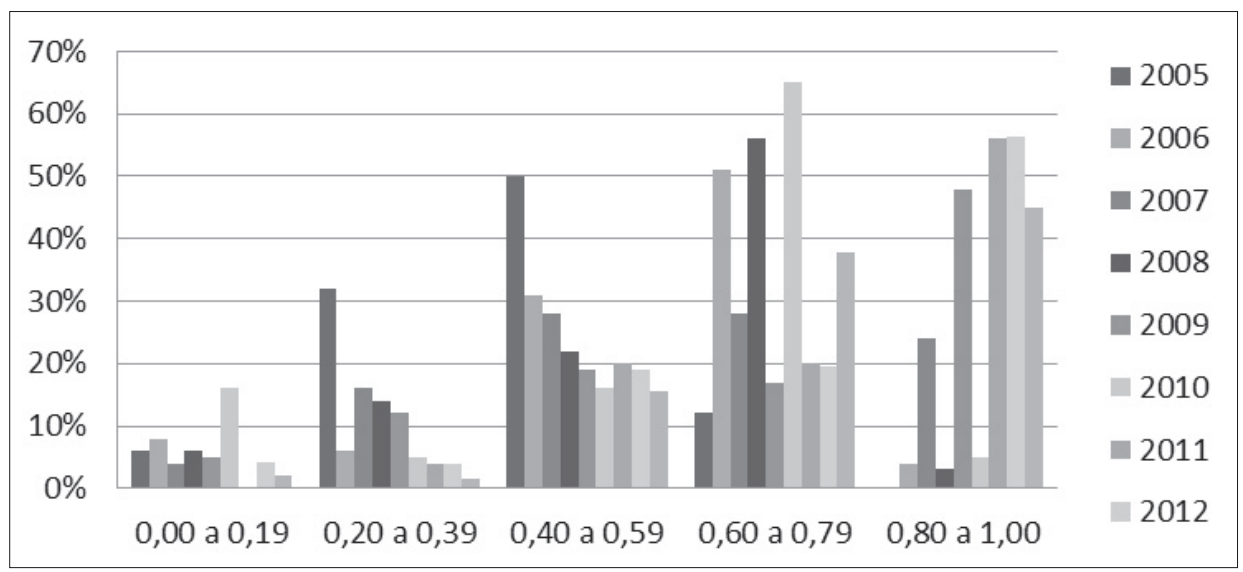

Como pode ser visto, em linhas gerais, os resultados do IDSS mostram a manutenção no comportamento dos indicadores que parecem estar contribuindo na indução do mercado no sentido do alcance das diretrizes estratégicas estabelecidas pela ANS, traduzidas pelas dimensōes e indicadores do Programa.

Outro ponto a ser destacado é que, além da iniciativa de gerar informações que possam contribuir de certo modo para o fortalecimento do poder de escolha pelo beneficiário da operadora a ser contratada, a ANS vem promovendo esforços para a disseminação de informações de qualidade com vistas ao desenvolvimento setorial. Dessa forma, com a análise dos resultados ano a ano (2004-2014), identificou-se que os atuais planos de saúde mostram maior qualificação com relação aos anos anteriores. Essa constatação, segundo Leal e Matos (2009), evidencia, através do IDSS, uma evolução positiva na qualidade das operadoras, que, sem dúvida, se reflete na expectativa de melhoria na oferta de serviços ao beneficiário. 
Contudo, Escrivão Júnior e Koyama (2007), a respeito dos dados fornecidos que sustentam a elaboração do IDSS, denunciam que, em relação à confiabilidade das informações fornecidas pelas operadoras para o IDSS, não há formas sistemáticas previstas para garantir a validade dos dados pela ANS no PQSS.

Outra questão relacionada a esse pano de fundo regulatório é o crescente movimento de concentração do mercado de operadoras de planos de saúde, dada a redução significativa do número de empresas desde que o IDSS foi implantado em 2005. Para Ocké-Reis (2004), quando a ANS uniformiza as regras de funcionamento do mercado, fiscaliza as irregularidades econômico-financeiras das operadoras e elimina as empresas fraudulentas, paradoxalmente, acaba favorecendo a concentração do mercado em favor dos oligopólios privados.

Nesse caso - como previne Mazzucchelli em um sentido geral -, isso significaria “[...] não apenas a fusão dos distintos capitais ou a anexação dos mais débeis aos mais fortes, mas acima de tudo o controle do capital social por um grupo cada vez mais reduzido de capitalistas" (MAZZUCCHELLI, 1985, p. 93).

Segundo dados da ANS (2016), em dezembro de 2006, havia 1.610 empresas operadoras de planos privados de saúde. Em junho de 2016, esse número havia diminuído para 1.112 operadoras ativas de planos privados, o que representou uma redução de aproximadamente $31 \%$ de empresas operando no setor.

Essa preocupação em relação à concentração do setor se acentua à medida que o capital estrangeiro, autorizado legalmente, vem comprando empresas de grande porte de planos de saúde privados, tais como Amil e a HAPVIDA, detentoras de uma vasta cartela de beneficiários.

Todavia, a despeito dessas limitaçôes, os dados parecem mostrar uma importante evolução do setor privado no que tange à busca pela qualificação, especialmente nos últimos quatro anos, quando a comparabilidade dos índices é maior em função da estabilidade do acervo de indicadores.

Nesse sentido, ao avaliar o desempenho da ANS e das operadoras de planos privados de saúde, o Programa de Qualificação da Saúde Suplementar parece buscar não apenas classificar, mas abrir possibilidades para acréscimos de qualidade 
ao modo de fazer dessas instituiçõos, de maneira que elas se responsabilizem pela produção de serviços de saúde, que de fato contribuam para elevar os níveis de saúde dos brasileiros cobertos por planos privados. Nessa direção, os dados tendem a afirmar que, embora a avaliação ainda seja tecnocrática, o movimento em prol da qualificação das ações e serviços à saúde está sendo feito pela a ANS.

A longitudinalidade e a sistematização do IDSS indicam que, ao contrário do que é perceptível nas estratégias de avaliação de desempenho do sistema público de saúde, existe no sistema privado uma sólida orientação da avaliação por resultados (OLIVEIRA, 2013), ainda que se questione sob que interesses advoga a ANS, segundo Ocké-Reis e Sophia (2009).

Sendo assim, conforme Ocké-Reis (2004), tanto a critica da gestão tecnocrática quanto do modelo regulatório da ANS indicam a necessidade de a assistência à saúde ser encarada como um direito social específico no âmbito do mercado, cuja materialização exigiria mudanças na Constituição, de modo que a regulação dos planos de saúde - orientada pelo interesse público - fosse reforçada pela adoção de um regime de concessão dos serviços públicos.

\section{Considerações finais}

É inegável a importância da qualificação para o setor saúde, tanto quanto sua própria regulamentação. $\mathrm{Na}$ verdade, a qualificação do setor já estava na agenda regulatória antes mesmo da criação da ANS. Contudo, considerando a dualidade do sistema de saúde brasileiro, legitimada inclusive na Constituição Cidadã, dado o atual cenário nacional do setor saúde, fica claro que uma política de qualificação do setor suplementar de saúde gera influências tanto no público quanto no privado. Por conta disto, deveria haver um maior alinhamento do Ministério da Saúde nas estratégias de avaliação de desempenho dos dois sistemas. Nessa direção, a escassez de trabalhos sobre a qualificação da saúde suplementar sinalizada por este artigo parece evidenciar a negação de que a imbricação entre o público e o privado do setor saúde influencia diretamente nos caminhos e descaminhos do SUS.

No que tange ao desenvolvimento do IDSS, a revisão dos resultados do programa de qualificação da ANS mostrou que a utilização da metodologia de avaliação proposta pelo índice tem contribuído em tornar públicos os graus de 
qualidade do setor da saúde suplementar, munindo o usuário / consumidor / beneficiário de informações que o auxiliem em suas escolhas, tanto na adesão quanto na portabilidade, proporcionando, assim, maior transparência ao setor.

Foi também observado que as operadoras utilizam amplamente seu resultado positivo no IDSS como marketing para atrair consumidores e até mesmo para fidelizar seus beneficiários. Tal prática retrata o impacto direto que o IDSS causa no mercado concorrencial da saúde privada. Esse acirramento da concorrência pode ser favorável ao beneficiário, de certo modo, quando a competição gera redução dos prêmios. No entanto, o problema reside no impacto negativo gerado pela concentração do mercado, quando os grandes players acabam atuando como oligopsônios, achatando os preços dos prestadores médico-hospitalares, o que poderia prejudicar a qualidade da atenção médica prestada aos consumidores, sobretudo os usuários cobertos pelos planos individuais de segunda linha (OCKÉ-REIS, 2004).

Considerando os atores sociais envolvidos no setor da saúde suplementar, Carvalho e Cecílio (2007) concluíram que estes possuem interesses divergentes e muitas vezes inconciliáveis. Assim como o próprio processo de regulamentação do mercado pela ANS, os resultados do IDSS têm sido também objeto de peleja e disputa entre as operadoras, como era de se esperar. Entretanto, verificouse, por fim, neste estudo, que a qualificação é o espaço onde esses "interesses divergentes" parecem dialogar.

Nesse sentido, cabe, então, aos reguladores o desafio de encontrar um equilíbrio entre evitar a "captura regulatória" por interesses privados e manter um diálogo produtivo com os entes regulados, para garantir que os regulamentos produzidos sejam realistas e eficazes (LISBÔA, 2015). Sobretudo, cabe à ANS proceder à sua regulação norteada pelo interesse público, em primeira instância alinhada aos interesses do SUS e a posteriori aos dos beneficiários.

Diante do exposto, constatou-se que realizar um estudo sobre a política de qualificação da saúde suplementar, além de contribuir para a construção do conhecimento sobre essa temática, é sobretudo pensar o sistema dual de saúde brasileiro sobre outra ótica. Assim, acredita-se que os estudos que analisam a saúde, fundamentados na ideia de que o sistema de saúde nacional é dual, são de extrema importância para construção do SUS. ${ }^{6}$ 


\section{Referências}

AGÊNCIA NACIONAL DE SAÚDE SUPLEMENTAR (ANS). Caderno de Informações da Saúde Suplementar: beneficiários, operadoras e planos. Rio de Janeiro: ANS, 2016.

. Mudança no IDSS 2016 / Ano base 2015. Disponível em: <http://www.ans.gov.br/ planos-de-saude-e-operadoras>. Acesso em: 05 jul. 2016b.

. Relatório Anual do Programa de qualificação da saúde suplementar. Rio de Janeiro: ANS, 2014.

AGÊNCIA NACIONAL DE SAÚDE SUPLEMENTAR. Dispõe sobre o Programa de Qualificação de Operadoras e dá outras providências. Resolução Normativa (RN) no 282, de 20 de dezembro de 2011. Disponível em: <http://www.ans.gov.br/legislacao/busca-delegislacao>. Acesso em: 05 jul. 2016.

AGÊNCIA NACIONAL DE SAÚDE SUPLEMENTAR. Dispõe sobre o Programa de Qualificação de Operadoras e dá outras providências. Resolução Normativa (RN) no 139 , de 24 de novembro de 2006. Disponível em: <http://www.ans.gov.br/legislacao/busca-delegislacao>. Acesso em: 05 jul. 2016

BAHIA, L. O SUS e os desafios da universalização do direito à saúde: tensões e padrões de convivência entre o público e o privado no sistema de saúde brasileiro. In: LIMA, N. et al. (Org.) Saúde e democracia: história e perspectivas do SUS. Rio de Janeiro: Ed. FIOCRUZ, 2005. p. 407-449.

BAHIA, L.; VIANA, A. Breve histórico do mercado de planos de saúde no Brasil. In: BRASIL. Ministério da Saúde. Regulação e saúde: estrutura, evolução e perspectivas da assistência médica suplementar. Rio de Janeiro: ANS, 2002. p. 132.

BRASIL. Lei n. 9.961/2000. Dispõe sobre a criação da ANS. Brasília, 2000a. Lei no 9.656. Dispõe sobre os Planos de Assistência à Saúde. Brasília, 1998.

CAETANO, J.C.; PRADO, M.L.; PIETROBON, L. Saúde Suplementar no Brasil: o papel da Agência Nacional de Saúde Suplementar na regulação do setor. Physis: Revista de Saúde Coletiva, Rio de Janeiro, v. 18, n. 4, p. 767-783, 2008.

CARVALHO, E.B.; CECÍLIO, L.C. de O. A regulamentação do setor saúde suplementar no Brasil: a reconstrução de uma história de disputas. Cadernos de Saúde Pública, v. 23, n. 9, p. 2.167-2.177, set. 2007.

COSTA, N.R. O regime regulatório e o mercado de planos de saúde no Brasil. Ciência e Saúde Coletiva, v. 13, n. 5, p. 1.453-1.462, 2008.

ESCRIVAO JUNIOR, A.; KOYAMA, M. F. O relacionamento entre hospitais e operadoras de planos de saúde no âmbito do Programa de Qualificação da Saúde Suplementar da ANS. Ciênc. saúde coletiva, Rio de Janeiro, v. 12, n. 4, p. 903-914, ago. 2007. 
FAVERET FILHO, P.; OLIVEIRA, P.J. A universalização excludente: reflexões sobre as tendências do Sistema de Saúde. Revista de Planejamento e Políticas Públicas, n. 3, p. 139-162, 1990.

LEAL, R.M.; MATOS, J.B.B. Regulação de preços e resultados econômicos dos planos de saúde no Brasil. Apresentado no IX Encontro Nacional de Economia da Saúde. 2009. Disponível em: <http://abresbrasil.org.br/sites/default/files/doc_abres_2009_-_36.pdf>. Acesso em: 8 de jul. de 2015 .

LISBÔA, R.M. Regulação e qualidade assistencial: o Programa QUALISS da ANS na perspectiva das operadoras de planos de saúde. 2015. 132 f. Dissertação (Mestrado em Saúde Pública) - Escola Nacional de Saúde Pública Sergio Arouca, Rio de Janeiro. 2015.

MAJONE, G. Regulating Europe. London: Routledge, 1996.

MALTA, D. C. et al. (Org.). Duas faces da mesma moeda: microrregulação e modelos assistenciais na saúde suplementar. Rio de Janeiro: Ministério da Saúde, 2005.

MAZZUCCHELLI, F. A contradição em processo. São Paulo: Brasiliense, 1985.

OCKÉ-REIS, C. O. Challenges of the private health plans regulation in Brazil. Brasília: IPEA, 2004.

OCKÉ-REIS, C. O.; SOPHIA, D. C. Uma crítica à privatização do sistema de saúde brasileiro: pela constituição de um modelo de proteção social público. Saúde em Debate, v. 33, n. 81, p. 72-79, 2009.

OLIVEIRA, D.F. Os caminhos da avaliação de desempenho do setor saúde: os dois lados do mesmo sistema de saúde. Dissertação (Mestrado em Saúde Coletiva) - Instituto de Medicina Social, Universidade do Estado do Rio de Janeiro, Rio de Janeiro, 2013.

SANTOS, I.S. O mix público-privado no sistema de saúde brasileiro: elementos para a regulação da cobertura duplicada. Tese (Doutorado em Saúde Pública) - Escola Nacional de Saúde Pública, Rio de Janeiro, Fiocruz, 2009.

SCHEFFER, M.; BAHIA, L. The financing of campaigns by the plans and health insurance in the 2010 elections. Saúde em Debate, v. 37, n. 96, p. 96-103, 2013.

\section{Notas}

${ }^{1}$ Disponível em http://www.aihw.gov.au/.

${ }^{2}$ Disponível em http://www.scielosp.org/.

${ }^{3}$ Vale destacar que as faixas de IDSS de cada ano não são inteiramente comparáveis, visto que os respectivos índices de desempenho são resultantes de conjuntos de indicadores e critérios de pontuação que sofrem alguma modificação ano a ano. 
${ }^{4}$ A distribuição apresentada refere-se apenas a parcela das operadoras médico-hospitalares, excluindo-se as operadoras odontológicas.

${ }^{5} \mathrm{O}$ termo captura refere-se à condição em que o órgão regulador toma decisões técnicas baseadas no atendimento aos interesses específicos dos agentes econômicos regulados, numa afronta flagrante à própria razão de existir de um órgão regulador.

${ }^{6}$ D.F. de Oliveira participou da concepção, análise e interpretação dos dados e redação do artigo. G.E.M. Kornis participou da análise e interpretação dos dados, redação e revisão crítica do artigo. 
Policy for qualification of supplemental health in Brazil: the role of the Supplemental Health Performance Index

This is an exploratory literature review that aimed to understand the role of the Supplemental Health Performance Index (IDSS) Program of Health Plans Operators Qualification, prepared by the National Health Agency (ANS-PQSS). The working proposal was to increase knowledge about the history of this index as well as the impact of its use for regulation and industry concentration by analysis of official documents and academic papers written on the subject. We noticed that the academic literature is extremely scarce on this subject, which alone justifies the need for further study of the PQSS. The research concluded that the instrument used by the NSA is effective, democratic and participative regarding the achievement of objectives of the Education Program of the Health Plan Operators, and promoted greater transparency to the private subsystem. However, it was also found that the IDSS had a discriminating and concentrating role of the market in favor of private oligopolies, going against the normative principles of the ANS on consumer protection, regulated competition and public interest.

> Keywords: supplemental health; health system assessment; information system; qualification program. 